\title{
LA CAMPAÑA PRESIDENCIAL DE VICENTE FOX Y EL MODELO PROPAGANDISTA DE COMUNICACIÓN POLÍTICA
}

\author{
Vicente Fox presidential campaing and the model of propaganda \\ in political communication
}

\author{
Adriana BORJAS BENAVENTE \\ Universidad Champagnat y Universidad del Valle de México \\ olioscolida@yahoo.com.mx
}

BIBLID [1130-2887 (2003) 33, 101-121]

Fecha de recepción: febrero del 2003

Fecha de aceptación y versión final: marzo del 2003

RESUMEN: Con base en las características atribuidas por Dominique Wolton a la comunicación política, es posible situar el surgimiento pleno de esta última en México durante el proceso electoral de 1988, cuando los discursos de la opinión pública a través de los sondeos comenzaron a introducirse en el espacio público. A partir de entonces, al producirse el intercambio de mensajes entre los actores con legitimidad, empezó a configurarse un modelo de comunicación política, cuyos rasgos esenciales surgieron o se reafirmaron durante la campaña para las elecciones presidenciales de julio de 2000 y que, en tanto coinciden con la tipología establecida por Gilles Achache, corresponden al modelo propagandista.

Dar cuenta de la campaña electoral de Vicente Fox, candidato del Partido Acción Nacional a la Presidencia de la República mexicana en el año 2000, establecer las diferencias que representó respecto a las campañas de otros candidatos, así como en relación al comportamiento tradicionalmente observado por los distintos actores políticos en épocas electorales anteriores, a efecto de demostrar que al introducir y privilegiar el uso de la mercadotecnia política en el espacio público, la campaña foxista constituyó un factor determinante en la configuración del modelo propagandista de comunicación política que actualmente existe en México, constituye el propósito de este trabajo.

Palabras clave: comunicación política, México, opinión pública, modelo propagandista, campaña electoral.

ABSTRACT: The characteristics of political communication identified by Dominque Wolton can be used to analyse the electoral process of 1988 in Mexico, as public opinion and opinion 
polls became a feature of public space. It is at this point that a model of political communication began to emerge through the exchange between legitimate political actors. The main features of this exchange emerged and were consolidated during the 2000 presidential election campaign, coinciding with the typology developed by Gilles Achache regarding a model of propaganda.

The objectives of the paper are to examine the electoral campaign of Vicente Fox of the PAN for the presidency in 2000, and to identify the differences that set it apart from the campaign of other candidates and from the traditional electoral behaviour of previous electoral processes, in order to demonstrate that through the use of techniques of political marketing in the public space, the Fox campaign introduced a new model of propaganda in political communication in Mexico.

Key words: political communication, Mexico, public opinion, propaganda model, electoral campaign.

En México, la fundación en 1929 del partido político que aglutinó a los distintos grupos que participaron en la Revolución para distribuir alternadamente el poder entre ellos a lo largo de 71 años ${ }^{1}$, conllevó la configuración y consolidación de un sistema político de partido hegemónico-pragmático y no competitivo electoralmente ${ }^{2}$, e implicó además la conformación de un régimen presidencialista de carácter autoritario donde, desde la perspectiva del funcionalismo, el flujo de los mensajes políticos registra un carácter continuo entre el grupo gobernante y los ciudadanos, quienes disponen de canales escasos para transmitir mensajes a los que gobiernan ${ }^{3}$. El resultado: un papel predominante de la élite gobernante en el espacio público nacional al que gradualmente accedieron los medios de difusión masiva, y del que el resto de los actores políticos y el conjunto de ciudadanos permanecieron más o menos marginados.

Wolton (1998) define la comunicación política como «el espacio en que se intercambian los discursos contradictorios de los tres actores que tienen legitimidad para expresarse públicamente sobre política, y que son los políticos, los periodistas y la opinión pública a través de los sondeos»; además, y en la medida en que le atribuye un carácter regulador, puesto que mediante una serie de procedimientos permite el funcionamiento e intercambio de esos discursos contradictorios, la considera condición fundamental para el ejercicio de la democracia masiva. Con base en las características establecidas por Wolton es posible situar el surgimiento de la comunicación política en México durante el proceso electoral de 1988, cuando los discursos de la opinión pública a través de los sondeos empezaron a introducirse en el espacio público. A partir de

1. Me refiero al Partido Nacional Revolucionario (PNR), denominado a partir de 1946 Partido Revolucionario Institucional (PRI).

2. Retomo la definición del sistema político mexicano de Giovanni SARTORI en Partidos y sistemas de partidos. Madrid: Alianza Universidad, 1992, p. 279.

3. Fagen considera que las diferencias más relevantes de los flujos de comunicación política se relacionan con el tipo de régimen político, el cual puede ser democrático, autoritario o totalitario. Vid A. Panebianco. Comunicación política. En N. Bobbio, N. Mateucci y G. Pasquino. Diccionario de política. México: Siglo Veintiuno Editores, 1997, pp. 263-268. 
entonces, al producirse el intercambio de mensajes entre los actores con legitimidad, comenzó a configurarse un modelo de comunicación política, cuyos rasgos esenciales surgieron o se reafirmaron durante la campaña para las elecciones presidenciales de julio de 2000 y que, al coincidir con las características establecidas por Achache (1998), corresponden al modelo propagandista.

El modelo propagandista de comunicación política asume el carácter teológico de la propaganda en tanto que plantea «como instancia final una realidad trascendente» al espacio público, expresada a través de discursos impregnados de promesas y cuya esencia ideológica los hace indiscutibles e «infalsificables» (Achache, 1998: 116-117). La convicción en la propaganda depende de la fe de los receptores, los cuales conforman más un auditorio de espectadores que una asamblea en la que los asistentes participan. Achache (1998) subraya que el intercambio de papeles no se produce en el interior de este modelo, puesto que el emisor desempeña el papel de «guía», mientras que los receptores conforman una multitud de creyentes dominados por el afecto más que por la razón y es en ese sentido que la influencia que ejercen los discursos no radica en el contenido, sino en la forma y dinamismo que se les imprime. Las imágenes y las siglas son medios relevantes para el modelo propagandista de comunicación política, cuyo espacio público es compacto y homogéneo, en tanto que sólo incluye a quienes comparten el afecto común y la identidad del sentimiento.

Al dar cuenta de la campaña electoral de Vicente Fox, candidato del Partido Acción Nacional a la Presidencia de la República en el año 2000, establecer las diferencias que aquélla presentó respecto a las campañas de los otros candidatos, así como en relación con el comportamiento tradicionalmente observado por los distintos actores políticos en épocas electorales anteriores, me propongo demostrar que al introducir y privilegiar el uso de la mercadotecnia política en el espacio público, la campaña foxista constituyó un factor determinante en la configuración del modelo propagandista de comunicación política que he afirmado existe actualmente en México.

Aun cuando la introducción de los discursos de la opinión pública a través de los sondeos en el espacio público significó la ampliación de éste y el surgimiento formal de la comunicación política a finales de la década de 1980, el papel regulador que Wolton (1998) atribuye a aquélla fue asumido por el régimen el cual, a efecto de garantizar la permanencia de la élite gobernante, aplicó un criterio selectivo que privilegiaba la expresión de los discursos de algunos actores políticos, al tiempo que contenía o desalentaba la expresión de otros. Fue así como en el intercambio de los tres discursos contradictorios de los actores de la comunicación política prevaleció el de los gobernantes y militantes del Partido Revolucionario Institucional (PRI), el de los medios aquiescentes al sistema político establecido y el de la opinión pública que mediante los sondeos aprobaba el comportamiento de los gobernantes y se manifestaba a favor de que permanecieran en el poder. Es en este sentido que desde un primer momento, y en razón de que no todos los actores eran iguales, puesto que no se les reconocía «la competencia para tomar la palabra» (Achache, 1998: 114), la comunicación política en México surgió alejada del modelo dialógico, el cual establece como requisito 
indispensable la racionalidad, libertad e igualdad de quienes intercambian discursos en el espacio público ${ }^{4}$.

Lejos de un discurso racional que implicara la definición de una identidad política y de conceptos ideológicos claros, así como la enunciación de propuestas concretas que permitieran distinguir los distintos proyectos políticos coexistentes, los actores más o menos excluidos por el régimen del espacio público proclamaron la democracia como la «realidad trascendente» y se concentraron fundamentalmente en propugnarla, al tiempo que reclamaron una y otra vez la apertura de los medios de difusión masiva a todos los actores del espacio público.

A efecto de recuperar la legitimidad perdida en las elecciones de $1988^{5}$ y de mantener el control amenazado por cambios imprevistos en los distintos ámbitos de la vida nacional, e interesado en incorporar al país al proceso internacional de globalización, el régimen priísta, encabezado por el presidente Carlos Salinas de Gortari y, a partir de 1994 por Ernesto Zedillo, implementó una serie de estrategias más o menos exitosas de carácter económico, político y social que le permitieron conservar el respaldo de los sectores aliados, y comenzó a responder gradual y selectivamente a algunas de las exigencias planteadas por los actores políticos de oposición que, por consiguiente, y en la medida en que accedieron a espacios de poder pudieron impulsar, y conducir cambios sustanciales, entre los que destaca la reforma a la Ley Electoral que, desde fines de 1996, garantizó la realización de comicios más limpios y equitativos que aceleraron los avances electorales y se tradujeron en triunfos cada vez más significativos para el Partido Acción Nacional (PAN) de centro derecha y para el Partido de la Revolución Democrática (PRD) de centro izquierda .

La subordinación a los dictados del régimen por parte de algunos medios de difusión masiva, agudizada durante la Presidencia de Salinas de Gortari (1988-1994), deterioró casi por completo la legitimidad informativa y la credibilidad en ellos entre amplios sectores de la población, los cuales optaron por fortalecer a aquellos medios que en el transcurso de los últimos años habían acreditado una vocación independiente. En estas circunstancias, y a efecto también de recuperar la legitimidad y credibilidad perdidas,

4. Para profundizar vid. G. Achache. El marketing político. En J. M. Ferry, D. Wolton et al. El nuevo espacio público. Barcelona: Gedisa, 1998, pp. 112-116.

5. El resultado oficial de las elecciones federales del 6 de julio de 1988 que confirió el triunfo al candidato presidencial del PRI Carlos Salinas de Gortari fue ampliamente cuestionado. En México existe la convicción de que ese día el régimen priísta perpetró un fraude electoral mayúsculo para conservar el control de la Presidencia de la República. Existe una amplia bibliografía al respecto, gran parte de ella se encuentra consignada en A. BORJAS BENAVENTE. Estructura, organización interna y desempeño público del Partido de la Revolución Democrática: 1989-2000. Tesis doctoral. Universidad de Salamanca, España, diciembre de 2001. Merece la pena ver también Jorge CASTAÑEDA. La herencia. Arqueología de la sucesión presidencial. México: Extra Alfaguara, 1999, passim.

6. Para profundizar vid. A. BORJAS BENAVENTE. Estructura, organización interna..., op. cit.; y Estrategias de campaña del PRI, del PAN y del PRD en las elecciones del Distrito Federal de 1997. Comunicación presentada en el III Congreso Español de Ciencia Política y de la Administración. Salamanca, España, octubre de 1997. 
los distintos medios ensayaron la apertura gradual de sus espacios informativos y de opinión a los discursos de los actores de la comunicación política hasta entonces excluidos (Borjas Benavente, 2001). Fue de esta manera cómo paulatina aunque intermitentemente, algunas de las demandas y acciones de quienes se oponían al régimen priísta comenzaron a formar parte de la agenda de los medios masivos. Este hecho, en algunos casos y tal y como lo plantean quienes investigan los efectos de agenda, influyó en las preferencias políticas de algunos electores (Bregman, 1998) ${ }^{7}$.

Es importante destacar que muchos medios mantuvieron su lealtad al régimen priísta y con el propósito de que éste fuera refrendado en el poder lo ensalzaron, al tiempo que omitieron, distorsionaron y criticaron las acciones y discursos de los demás actores políticos. Este hecho terminó por provocar el efecto contrario, por lo menos en una parte de la audiencia, que no sólo rechazó la información recibida, sino que incluso comenzó a sentir simpatía hacia los actores criticados por los medios. En este sentido resulta pertinente mencionar cómo «el público ejerce una percepción selectiva con respecto de todos los aspectos de la comunicación: los medios tal vez organicen el calendario y la jerarquía de los acontecimientos, pero esto no impide que la opinión, llegado el caso, los rechace» (Bregman, 1998: 216).

En un contexto en el que se desdibujaban algunos de los rasgos más autoritarios del régimen, en el que la exclusión de actores del espacio público de la comunicación política disminuía, y en el que el cambio de circunstancias de toda índole hacía plausible la alternancia en el poder ejecutivo y, a partir de ella, la instauración de un sistema político democrático, se llevaron a cabo las campañas de los partidos políticos para conquistar la Presidencia de la República en las elecciones del 2 de julio del 2000 .

\section{LA CAMPAÑA FOXISTA: INDUCCIÓN DE UNA FORMA DISTINTA DE HACER POLÍTICA}

El 2 de julio de 1998, exactamente dos años antes de las elecciones presidenciales de 2000, Vicente Fox Quesada, gobernador panista del estado de Guanajuato, anunció que deseaba ganar la Presidencia de la República y, a través de acciones, discursos y de una estrategia de mercadotecnia política invitó a los ciudadanos a conquistar «el futuro juntos» (Beltrán del Río, 1998: 25). La irrupción inesperada de un político que abiertamente manifestaba sus pretensiones, inauguró una forma distinta de hacer política e imprimió un ritmo diferente a los tiempos electorales.

Hasta entonces e independientemente del partido político al que pertenecieran, quienes aspiraban a obtener cualquier tipo de candidatura eludían reconocer o incluso negaban públicamente dichas pretensiones, aunque no sin mencionar su vocación

7. Para profundizar en torno a los resultados obtenidos por quienes estudian la función de agenda y los efectos producidos vid. en D. BREGMAN. La función de agenda: una problemática de transformación. En J. M. FERRY, D. WOLTON et al. El nuevo espacio público. Barcelona: Gedisa, 1998, pp. 210-223. 
de servicio y, por tanto, la disponibilidad a ser postulados. La campaña electoral a la Presidencia se iniciaba formalmente con la designación o «destape» del candidato del PRI a la Presidencia, la cual generalmente se llevaba a cabo nueve o diez meses antes de los comicios y concluía el domingo anterior a la realización de éstos. En muy pocas ocasiones quienes aspiraban o habían obtenido la candidatura de los otros partidos políticos se adelantaban a los tiempos electorales impuestos por el Revolucionario Institucional. Al transgredir dos reglas no escritas del sistema político mexicano, Fox provocó el disgusto de los demás actores políticos, puesto que les obligó a acelerar decisiones y estrategias que les permitieran reaccionar de manera puntual a la cuenta regresiva iniciada con premura.

Al expresar abiertamente su deseo de conducir al país y, por consiguiente, adelantar y prolongar el tiempo de la campaña electoral Fox asumió la iniciativa respecto a sus adversarios políticos y por ello se colocó a la cabeza de la competición por la Presidencia de la República; además, al interior de Acción Nacional, también impuso nuevas formas y tiempos. Desde febrero de 1998, a través de la creación de Amigos de Fox, una estructura que al operar de la misma manera que las redes comerciales de Estados Unidos, es decir, mediante el convencimiento de persona por persona ${ }^{8}$, el gobernador de Guanajuato consiguió allegarse recursos materiales y económicos para la campaña pero, sobre todo, imponerse como el candidato idóneo del $\mathrm{PAN}^{9}$, en tanto que demostró una base social de apoyo plural que numéricamente rebasaba la membresía panista $^{10}$. Los sondeos, que al dar inicio la campaña foxista indicaron que únicamente $18 \%$ de los mexicanos conocían a Fox, en mayo de 1999 registraron que éste era conocido por más del 70\% de los electores potenciales (Borjas Benavente, 2001). En este contexto fue que sin disputas ni rupturas, el Partido Acción Nacional postuló en noviembre de 1999 la candidatura a la Presidencia de Vicente Fox, quien al sumar el respaldo

8. «Cada amigo convence por lo menos a otras cinco personas para entrar a la organización, que se estructura en grupos de 70 ciudadanos afiliados mediante «cadenas telefónicas», casa por casa o por Internet. El objetivo: llegar a aglutinar 20 millones de personas y cubrir con dos representantes las casillas el día de la elección. F. ORTIz PARdo y F. Ortiz PINChetTi. En detalle, la gigantesca organización que mueve a Fox. Proceso, n ${ }^{\circ}$ 1215, 13 de febrero, 2000, pp. 28-31.

9. En México para participar en elecciones los candidatos deben ser registrados por lo menos por un partido político, también a su vez legalmente registrado. Al interior de Acción Nacional, las preferencias se decantaban a favor otros militantes de trayectoria más amplia o significativa que la de Fox. Ellos eran: Francisco Barrio, quien había sido gobernador del estado de Chihuahua; Diego Fernández de Cevallos, candidato del PAN a la Presidencia de la República en las elecciones de 1994; y Ernesto Ruffo, quien al asumir en 1989 el poder ejecutivo del estado de Baja California en 1989 se convirtió en el primer gobernador del PAN, que desde su fundación en 1939 había participado sin obtener resultados en las elecciones estatales. Vid. A. BorJAS BENAVENTE. Estructura, organización interna y desempeño público del Partido de la Revolución Democrática: 1989-2000. Tesis doctoral. Universidad de Salamanca, España, diciembre, 2001.

10. En julio del 2000, el PAN registraba 490.000 personas entre las que se encontraban miembros activos y simpatizantes, en tanto que para esa misma fecha los Amigos de Fox informaban contar con 5 millones de simpatizantes (BORJA BENAVEnTE, 2001: 409). 
del Partido Verde Ecologista de México (PVEM), se registró oficialmente como candidato de la coalición electoral Alianza por México ${ }^{11}$.

Desde un primer momento la campaña de Fox, articulada y conducida por la mercadotecnia ${ }^{12}$, consideró a los electores como clientes a los que había que conceder la razón y satisfacer. Con base en estudios de mercado que recababan las demandas y propuestas de los distintos segmentos, los banqueros, la jerarquía eclesiástica, los empresarios, los campesinos, las amas de casa, los burócratas, los estudiantes, los pobres, los pequeños comerciantes, en suma, cada sector, escuchó las promesas que quería escuchar $^{13}$. Las inconsistencias y la contraposición de intereses apenas se percibían en el contenido de los discursos, centrados fundamentalmente en la idea de cambio, el cual daría lugar a la «realidad trascendente» que caracteriza el modelo propagandista de comunicación política. En todo momento Fox se presentó y fue reconocido por sectores cada vez más amplios como el guía conductor del cambio. Este reconocimiento se explica, desde la perspectiva de la comunicación política, por el hecho de que la personalidad del candidato integraba aspectos diversos: provinciano, perteneciente a una familia de clase media alta sin relaciones políticas, profesional, ranchero y empresario exitoso, político de oposición con experiencia gubernamental, católico, separado de su mujer pero a cargo de los cuatro hijos adoptados durante el matrimonio, de carácter extrovertido, seguro de sí mismo, sencillo y sincero. Estos y otros rasgos aunados a la trayectoria y experiencias en los diversos ámbitos de la vida pública y privada de Vicente Fox le permitían presentarse como un hombre capaz y confiable, y con posibilidades reales de éxito.

Lo antes descrito permite relacionar el liderazgo foxista con el proceso de construcción de la legitimidad del emisor que se produce en el ámbito de la comercialización política, en la medida en que «opera mediante la acumulación de rasgos que, situados de un extremo al otro, constituyen lo que se llama una «imagen» o, más psicológicamente, una «personalidad». La tarea del que quiere intervenir en el campo de la comunicación política es integrar en sí mismo la mayor cantidad posible de rasgos, a fin de que con su asociación se componga, en el cuerpo social, la mayor cantidad posible de segmentos. De esta manera, no resulta útil intentar componerlos todos, puesto que basta reunir sobre sí el 51\%» (Achache, 1998: 122). Votar por Fox constituyó una apuesta por la transformación del país, representó la esperanza de que las condiciones

11. El PVEM aportó recursos financieros y estructura a la campaña de Fox. A cambio, introdujo algunas candidaturas al poder legislativo en algunos distritos electorales y sus discursos y propuestas fueron retomados por el candidato a la Presidencia.

12. Además de poseer un rancho próspero en el estado de Guanajuato, Fox se desempeño durante muchos años como ejecutivo de Coca Cola, donde incluso llegó a ser presidente para América Latina. Éste explica su visión empresarial y su amplio conocimiento de la mercadotecnia.

13. Explicación de Guillermo H. Cantú, integrante del equipo de campaña de Vicente Fox, entrevistado por José Gutiérrez Vivó el lunes 25 de junio en el programa Monitor. Cantú es además autor del libro Asalto a palacio. Las entrañas de una guerra (México, 2001), en el cual se narra el diseño y práctica de la estrategia electoral de Fox y que fue citado sin especificar editorial en la mencionada entrevista. 
de cada ciudadano mejorarían y, sobre todo, planteó la posibilidad de conseguir lo que hasta entonces parecía imposible, es decir, que la Presidencia del país fuera asumida por un candidato no prísta.

A diferencia de los candidatos panistas que le precedieron, Fox se adentró en territorios hasta entonces impenetrables o poco explorados por los candidatos opositores: en el campo buscó el voto de los campesinos, con quienes compartió sus experiencias agrarias, puesto que él mismo poseía un rancho en el estado de Guanajuato, hecho que además le permitía hacer ofertas más acordes con las necesidades reales de las zonas rurales. Los grandes empresarios, hasta entonces partidarios del PRI, y el sector productivo en general, acogieron el discurso de Fox, quien como empresario conocía los principales problemas que enfrentaban y, sobre todo, se comprometía a alentar la producción para superar las condiciones económicas del país. Es importante destacar que más allá del discurso dirigido a cada sector, el candidato de Alianza por el Cambio consiguió la adhesión de una parte significativa de la población, puesto que al proclamarse católico y enarbolar el estandarte de la Virgen de Guadalupe asumió uno de los rasgos más importantes de la identidad mexicana, además, al mismo tiempo desafió el anticlericalismo del régimen, cuyos ataques sólo sirvieron para reforzar entre la multitud creyente la certeza del triunfo del candidato guadalupano. Ante las críticas cada vez más insistentes por el uso de la mercadotecnia, los encargados de la campaña de Alianza por el Cambio afirmaban: «La mercadotecnia no inventa a Vicente; al revés; toda la mercadotecnia se basa en lo que es Vicente» (Borjas Benavente, 2001: 410), quien en todo momento consiguió mantener la iniciativa e imponer el ritmo y contenidos de la campaña electoral.

Los mítines de Alianza por el Cambio se efectuaron bajo el criterio estratégico del «encajonamiento», esto es, llevando a cabo la instalación de estrados bajos para que las cámaras de los medios de difusión no pudieran captar dónde se diluía la concentración de asistentes a los espacios públicos. Esto permitía apreciar reuniones multitudinarias que respaldaban las afirmaciones de Vicente Fox respecto a que cada vez eran más los que se sumaban a la esperanza del cambio. El PRI ya no pudo, como lo había hecho hasta entonces, descalificar a la oposición subrayando su carácter «minoritario». Otra estrategia para ampliar el intercambio de mensajes políticos fue la producción cada sábado al mediodía del programa radiofónico Fox en vivo, Fox contigo que, transmitido en cada entidad federativa, permitió difundir la información que otros medios masivos omitían o precisaba y ampliaba aquella que se había distorsionado o reseñado de manera breve o confusa. Además, en el programa los receptores planteaban directamente sus demandas y eran invitados a integrarse a los Amigos de Fox, mientras que el propio candidato dirigía un mensaje sobre un tema específico e interactuaba con la audiencia. A través de la aplicación de ambas estrategias Alianza por el Cambio impidió o consiguió contrarrestar los intentos de manipulación o distorsión de la información sobre los resultados obtenidos por la campaña foxista.

La democracia constituía la realidad trascendente a la que llegaría México con el triunfo de Fox. Esta realidad había sido propuesta con insistencia desde fines de la década de 1980 por el Partido de la Revolución Democrática y había dado lugar a una 
lucha difícil, cuyo máximo representante era Cuauhtémoc Cárdenas, quien una y otra vez había subrayado la importancia de propiciar y conseguir la instauración de un régimen democrático. Elaborado desde un criterio dialógico, el discurso del PRD era fundamentalmente racional, construido con argumentos que por su contenido sustancial y por su extensión hacían compleja la recepción y, más aún la comprensión del mensaje por parte de los receptores. En contraste, Vicente Fox expresó en lenguaje coloquial un mensaje sencillo, unívoco y, sobre todo, que resumía el deseo de muchos ciudadanos y sintetizaba la condición esencial para instaurar la democracia: «Sacar al PRI de Los Pinos», esto es, de la residencia donde oficialmente habitan los presidentes de la República.

Es importante subrayar que ninguno de los candidatos que participaron en la campaña de 2000 definió con precisión los términos utilizados en sus respectivos discursos, por lo que es posible preguntar, al igual que Javier del Rey (1997: 33), si el uso de términos tales como cambio, democracia e igualdad «¿describen algo sobre lo que los demás estemos de acuerdo, o se limitan a ejecutar acrobacias con palabras cargadas de prestigio y de ambigüedad?». Aunque lejos de una definición precisa que diera consistencia racional al mensaje político de cada candidato, lo cierto es que la sencillez con la que Vicente Fox expresó el suyo lo hizo más claro y comprensible y, por consiguiente, hizo más fácil su acogida en el ámbito afectivo, tal y como ocurre en el modelo propagandista.

En contraste con el discurso afectivo, breve e inclusivo de Vicente Fox, Cuauhtémoc Cárdenas, candidato de Alianza por México, integrada por varios partidos políticos de todo signo y encabezada por el PRD, presentaba su extenso programa de gobierno independientemente de que éste cumpliera o no las expectativas de los asistentes, por lo que sólo atraía la adhesión de quienes lo compartían. No obstante, los estrategas de la campaña cardenista estaban seguros del triunfo. La certeza la fundaban en la convicción de que el capital político acumulado durante más de una década por el líder moral del PRD y por tercera ocasión candidato a la Presidencia le otorgaba «amplias posibilidades de ganar en las elecciones del 2 de julio del 2000» (Borjas Benavente, 2001: 411). Además, lejos de la estrategia de campaña foxista, los colaboradores de Cárdenas expresaban: «No apostamos a la mercadotecnia. Entendemos la importancia de los medios como mecanismo para transmitir el mensaje político del candidato, pero Cárdenas le da tanta o más trascendencia al contacto directo con la gente. La idea rectora es combinar esa intensa actividad con una campaña inteligente de medios». El reto: provocar «una efervescencia masiva nacional que obligue a los medios a atender el discurso de Cárdenas en sus partes medulares» (Borjas Benavente, 2001: 411-412). La efervescencia no se produjo: para mayo de 1999, conforme a las encuestas, Fox se ubicaba en el primer lugar de las preferencias electorales, sitio en el que Cárdenas se había situado y mantenido durante un año ${ }^{14}$. De esta manera comenzó a resultar evidente cómo la opinión pública era más sensible a la forma y a las promesas que a los contenidos y a los hechos que las avalaban.

14. Encuesta de la empresa Indermec Louis Harris, apud ibid., p. 413. 
Además de las mismas promesas de siempre, Francisco Labastida, el candidato del PRI, añadía a sus discursos descalificaciones constantes e indirectas a la oposición. Pese al tradicional acarreo de militantes, los mítines prístas se desarrollaban sin el entusiasmo y euforia usuales, en tanto que la campaña en los medios de difusión masiva no conseguía el impacto esperado, puesto que las promesas no tenían una relación significativa con la realidad del país: el candidato ofrecía mejorar el sistema educativo mediante la instalación masiva de ordenadores en las escuelas públicas y la enseñanza obligatoria del inglés a los estudiantes de primaria, en un país donde más del 40 por ciento de la población se encontraba en condiciones de pobreza y carente del servicio de energía eléctrica, y donde casi un 10 por ciento de la población hablante de lengua indígena es monolingüe (Ponce, 2000). Ante las críticas, el equipo de campaña priísta argumentaba: «Es una campaña diferente. Es parte del nuevo PRI» y explicaba: «Decidimos no bombardear a la población, porque se puede llegar al saturamiento ante el electorado. Quisimos un ritmo pausado para que se conozca la propuesta de Labastida; por eso se definió que la campaña fuese de bajo perfil al inicio del año y que hiciéramos un esfuerzo creciente en adelante. Sin hacer muchos movimientos, nos guardamos nuestras mejores cartas, los recursos y la energía, para después» ${ }^{15}$. No fue así, lejos de mejorar, la campaña declinó cada vez más, y la iniciativa siguió siendo de Fox que al día siguiente de que Labastida se presentaba en un foro él acudía ahí mismo y era la actitud receptiva de los asistentes ante el candidato de Alianza por el Cambio lo que marcaba la diferencia. De esta manera, al concluir febrero de 2000, las encuestas del Grupo de Economistas y Asociados, otorgaban a Vicente Fox el 43,4 por ciento de las preferencias electorales y atribuían a Labastida el 36,6 por ciento, mientras que Cárdenas con porcentajes diversos se había desplazado al tercer lugar (Borjas Benavente, 2001: 413).

\section{LA ESTRATEGIA MERCADOTÉCNICA}

Alejado del tono grave y políticamente correcto con el que Cárdenas se refería a los asuntos nacionales y de la forma solemne y rebuscada con la que Labastida repartía las promesas del «nuevo PRI» ${ }^{16}$, Fox se expresaba con desparpajo, utilizaba los mismos giros del lenguaje que los demás ciudadanos, recurría a refranes, expresiones populares e incluso groserías y, sobre todo, proponía y respondía de manera contundente y unívoca, es decir, no daba lugar a malentendidos, no disfrazaba las palabras y

15. Palabras de Esteban Moctezuma Barragán, secretario general del PRI y coordinador general de la campaña de Labastida.

16. Francisco Labastida explica así el poco éxito de su campaña: «Parte del problema es que me pusieron a actuar. Actuar un papel que no era el mío. Me sentía inseguro al representar un papel [...] A excepción de los actos en los que me veía un poco mejor, lo demás era "oiga, ensaye tal frase, diga tal cosa". Qué flojera. Así no soy yo [...] Lo que los asesores decían: "lo que la gente desea ver o prefiere es esto". Y, a fin de cuentas, se trata de un equipo. Hay gente que se encarga de hacer una parte. A otros les toca el papel de candidato. Sin traicionar lo que uno es, se acomoda». Entrevistado por Gabriel Baducco. La muerte de las mariposas. Día siete, 2001, n 54, 1 de julio, pp. 20-27. 
cualquiera le entendía ${ }^{17}$, hecho que, en términos reales, reducía de manera significativa la distancia entre el candidato y los electores. Así, la estrategia política y electoral de Fox atendía con precisión las debilidades propias y de su partido para reducirlas y afianzaba y construía fortalezas que de manera insistente le permitían presentarse como el candidato de la alternancia.

A través de innovaciones constantes Vicente Fox consiguió imponer el paso a los aspirantes a la Presidencia, únicamente Cuauhtémoc Cárdenas se resistió. La presencia del candidato de Alianza por el Cambio, del candidato priísta y de otros participantes en la contienda por la Presidencia en programas cómicos de elevado raiting incrementó la presencia de cada uno de ellos en los medios (Monsiváis, 1999), los despojó de la solemnidad que hasta entonces había caracterizado a los actores de la política mexicana y los aproximó al público, pese a las ventajas que podía representar esta actitud, el candidato del PRD hizo campaña a su manera y, al igual que en campañas anteriores, concedió prioridad al contacto con la gente sobre el uso de los medios de difusión.

Aún cuando Cárdenas, Fox y Labastida, se refirieron al cambio y subrayaron la importancia de propiciarlo, sólo el candidato de Alianza por el Cambio consiguió transmitir la idea y personificarla ${ }^{18}$. No dejaba de resultar incoherente que Cárdenas hablara de cambio, cuando al postularlo por cuarta ocasión el PRD demostraba que ni siquiera podía cambiar de candidato en un país en el que no existe la práctica de postular al mismo candidato más de una vez. Asimismo, las promesas no cumplidas en el transcurso de 71 años de gobierno, anulaban la credibilidad en la oferta de cambio del candidato priísta.

Al despuntar la primavera de 2000 y ante el indiscutible avance de Vicente Fox la polarización del proceso electoral entre él y Francisco Labastida fue un hecho. Los intentos del equipo de campaña de Alianza por México para recuperar el segundo lugar en las preferencias electorales para Cuauhtémoc Cárdenas resultaron infructuosos, puesto que éste no conseguiría en adelante concentrar más del $22 \%$ de las predilecciones ${ }^{19}$. En este contexto se produjo la deserción de militantes del PRI y del PRD, que masiva y públicamente se sumaron a la base de apoyo del candidato de Alianza por el Cambio. $\mathrm{Al}$ respecto es posible considerar el surgimiento de una espiral del silencio al interior

17. Cuando le preguntaron si en el caso de ganar invitaría a Labastida a colaborar con su equipo de trabajo Fox contestó: «ni madres», en México, una clara e irrevocable negativa. A los niños les llama chiquillos; a las pequeñas empresas y comercios, «changarros»; define la civilidad política como el proceso en el que los legisladores «se golpeen hasta con la bacinica, pero al final del día sean capaces de alcanzar consensos»; reconoce que de joven se ponía unos «cuetes sabrosísimos», es decir, borracheras; y, durante la campaña, al referirse a algunos priístas les llamó «alacranes y víboras tepocatas».

18. Al respecto y para profundizar en la estrategia de Vicente Fox vid. F. ORTIZ PARDO y F. ORTIZ PinchetTi. En detalle, la gigantesca organización que mueve a Fox. Proceso, 2000, $\mathrm{n}^{\circ} 1215,13$ de febrero, p. 28 y Fox en campaña: ropa y comportamiento, según el auditorio. Proceso, 2000, n 1215, 13 de febrero, p. 31.

19. Encuesta del periódico Reforma y de Mund Opinion Services, p. 20. 
del Revolucionario Institucional y del Partido de la Revolución Democrática ${ }^{20}$, formada por los militantes que dudaban del triunfo de los candidatos postulados por sus propios partidos. La proliferación de encuestas que situaban a Vicente Fox a la cabeza diluyó la espiral y quienes vislumbraban el triunfo del candidato de Alianza por el Cambio terminaron por concederle su propio sufragio.

El discurso de Cuauhtémoc Cárdenas adquirió mayor precisión a efecto de reafirmar la propia identidad y la de las fuerzas que le respaldaban. Presentar a Alianza por México como la única alternativa de un gobierno honrado y con responsabilidad social; mencionar constantemente datos y cifras que indicaran un mayor conocimiento de la realidad del país y de cada uno de los auditorios y, sobre todo, subrayar la importancia de la ética en el ejercicio del poder y descalificar enfáticamente a la mercadotecnia, fueron los nuevos contenidos del discurso cardenista, cuyo propósito era marcar una diferencia sustancial con las promesas de los candidatos del PRI y de Alianza por el Cambio. Lejos de incrementar adhesiones, Cárdenas fue compelido por los asistentes a declinar a favor de Fox. Por consiguiente, y de la misma manera en que lo había hecho en 1994, el líder moral del PRD propuso la realización de dos debates: el primero sería con la presencia de los seis aspirantes a la Presidencia ${ }^{21}$; y, el segundo, con los tres que resultaran mejor evaluados en el primer debate.

Fox siguió avanzando, pues no sólo se comunicaba de una manera más espontánea y cercana, también introducía nuevas formas de llevar a cabo los actos públicos. Así, por ejemplo, pedía a los asistentes a los mítines que cargaran a sus hijos en hombros y prometía: «Ante estos chiquillos, ante nuestros hijos, me comprometo a dedicar cada latido de mi corazón, cada segundo y cada minuto de mi tiempo, para cambiar a nuestro querido México». Vicente Fox también pedía a los presentes que se comprometieran y dedicaran parte de su tiempo a conseguir diez votos más, es decir, a través de acciones de carácter emocional, involucraba afectivamente a la población, la hacía sentirse parte del cambio (Ortiz Pinchetti, 2000). Y obtuvo los resultados previstos.

En el debate de 90 minutos que se llevó a cabo el 25 de abril, participaron los seis candidatos a la Presidencia de la República, los cuales apenas tuvieron tiempo para exponer y argumentar la pertinencia de sus respectivas propuestas y, en un mensaje final, convocar a los ciudadanos a reflexionar el sentido del voto a partir del cambio de circunstancias que permitían vislumbrar un escenario político más competitivo. Al concluir, Vicente Fox aseguró: «Con la responsabilidad que significa ir adelante en la contienda presidencial, me comprometo ante todos ustedes a conformar un gobierno plural e incluyente; a integrar un proyecto común de nación, y a convocar a todos los mexicanos a un gran acuerdo nacional» (Ortiz Pinchetti y Ortiz Pardo, 2000: 20-21).

20. Para profundizar vid. E. Noelle-Neumann. La espiral del silencio. Una teoría de la opinión. En J. M. FerRY, D. Wolton et al. El nuevo espacio público. Barcelona: Gedisa, 1998, pp. 200209.

21. Manuel Camacho Solís, del Partido del Centro Democrático; Porfirio Muñoz Ledo, candidato del Partido Auténtico de la Revolución Mexicana; y Gilberto Rincón Gallardo, del Partido Democracia Social, eran los otros candidatos a la Presidencia de la República. 
Las encuestas continuaron acusando el avance del candidato panista, cuya estrategia fue entonces presentarse como la única alternativa para consumar el cambio y, por ello, invitar a todos los ciudadanos a que independientemente de su filiación política votaran por él. Enmarcado en la estrategia mercadotecnia Fox dejó de presentarse como candidato y comenzó a hablar como si ya hubiera ganado la presidencia de la República, hecho que contribuyó a avivar la fe en su triunfo.

Declarado por los sondeos como el perdedor del debate, Labastida exhortó a sus correligionarios a «defender el partido», sin embargo, al mismo tiempo comenzó a admitir la posibilidad de perder en las elecciones, hecho este último sin precedentes que, por consiguiente, alentó las esperanzas de triunfo de la oposición. Ante el rezago del candidato prísta, el equipo de campaña de Cárdenas intentó emprender una nueva estrategia que polarizara la competencia entre éste y Fox a partir de la comparación entre los proyectos de cambio que representaba cada uno de ellos, pero tampoco en esta ocasión obtuvo resultados significativos, ya que los contenidos afectivos se imponían sobre los argumentos estructurados racionalmente. Por su parte, el candidato de Alianza por el Cambio, fortalecido después del debate, insistió en convocar a «todos los mexicanos» a un acuerdo nacional que conllevara la suma de ideas y la construcción de consensos para garantizar que se concretara la transición democrática (Ortiz Pinchetti y Ortiz Pardo, 2000: 21).

A fines de abril, el Instituto Federal Electoral (IFE) dio a conocer que la equidad informativa que había prevalecido desde el inicio de las campañas se había roto de manera radical a favor de las candidaturas del $\mathrm{PRI}^{22}$. Por consiguiente, convencidos de que el régimen fraguaba un fraude electoral, el PAN y el PRD denunciaron las múltiples y tradicionales irregularidades cometidas por el Revolucionario Institucional en el transcurso de los distintos procesos electorales que se llevaban a cabo. Ciertos de que la oposición triunfaría en las elecciones presidenciales, Acción Nacional y el Partido de la Revolución Democrática compartían también la seguridad de que el régimen y el Revolucionario Institucional recurrirían a todo para impedirlo, por tanto, exhortaron a sus militantes y a los ciudadanos en general, a participar activamente para evitar anomalías en el proceso electoral. Por su parte, el IFE transmitió mensajes publicitarios en los medios electrónicos que alentaban a los votantes a expresarse libremente en las urnas y denunciar delitos electorales, mientras que los candidatos de oposición les pedían aceptar todos los beneficios que ofrecían los programas sociales del gobierno sin dejar que ello determinara el sentido de su voto.

En los primeros días de mayo el desplome del Revolucionario Institucional en las preferencias electorales, alentó la esperanza de atraer las preferencias electorales de los indecisos o decepcionados y, por tanto, conllevó un cambio de estrategias electorales,

22. Para profundizar en el tratamiento que los medios de difusión masiva dieron a la campaña electoral de 2000 vid. A. DELGADO. «Daños irreparables» al proceso electoral por la guerra de spots entre el IFE y la CIRT. Proceso, 2000, nº 1226, 30 de abril, pp. 32-35 y Montaño defiende a RTC y advierte: los concesionarios tendrán que reponer los spots que no transmitieron. Proceso, 2000, n 1226, 30 de abril, p. 34 . 
caracterizadas fundamentalmente por la descalificación del contrario: Fox atacó a Labastida, éste a Fox, y Cárdenas, que en otras campañas siempre había mantenido una actitud ecuánime en la que la crítica estaba dirigida al régimen y al PAN pero no a las personas, también agredió a Labastida, pero sobre todo a Fox ${ }^{23}$. Aunque intelectuales y académicos se manifestaron alarmados «por la degradación que se observa en nuestra vida política, por la ausencia en ella de un auténtico diálogo democrático y en peligro de una polarización creciente que redunde en una catástrofe para la nación» (Corro, 2000), la campaña se revitalizó en la medida en que resultaba un verdadero espectáculo. Las actividades, declaraciones y estrategias mercadotécnicas utilizadas en mayor o menor medida por los candidatos supusieron cada día un diálogo distinto que, informado por los medios masivos, confirmó el carácter propagandista de la comunicación política, el intercambio de discursos se intensificó con la plena participación de los tres actores con legitimidad. Atraídos, los electores reafirmaban, decidían o cambiaban el sentido de su voto. Conforme a los sondeos, Fox mantuvo la iniciativa y se fortaleció; Labastida, desconcertado, se debilitó aún más; y, reactivo, Cárdenas se mantuvo con gran dificultad en la contienda. Los estrategas de cada uno de ellos habían aprovechado o dejado pasar la oportunidad que les había ofrecido el nuevo escenario político (Borjas Benavente, 2001: 420).

A efecto de conjurar toda posibilidad de fraude electoral, a mediados de mayo Alianza por el Cambio difundió los resultados de sus propias encuestas, conforme a las cuales Fox registraba el 46,3 por ciento de las preferencias electorales, Labastida el 41,6 por ciento y Cárdenas el 9,3 por ciento ${ }^{24}$. Las disidencias se intensificaron, priístas, perredistas, dirigentes sindicales, ciudadanos sin partido pero identificados por su simpatía con la izquierda declararon públicamente su respaldo a Vicente Fox o se incorporaron a colaborar en su equipo de campaña ${ }^{25}$. Otros, los menos, y en su mayoría priístas, se

23. Graco Ramírez, candidato a diputado por el PRD, justificaba así la agresión de Cárdenas a Fox: «Ante la estrategia de un debate entre Cárdenas, Labastida y Fox, Cárdenas debe ir por la Presidencia. El que va arriba es Fox. Si fuera arriba Labastida, se iría contra él. Ésa es la estrategia que tenemos y creemos que es la válida: ir a ganar». A. DELGADO. Cárdenas y el PRD: historia de una declinación imposible. Proceso, 2000, $\mathrm{n}^{\circ}$ 1228, 14 de mayo, pp. 26-27.

24. «Ya somos más», inserto de la Alianza por México en Proceso, 2000, n 1228, 14 de mayo, p. 29.

25. Entre ellos, los académicos Adolfo Aguilar Zínser y Jorge G. Castañeda, simpatizantes de Cárdenas desde 1988 se sumaron como asesores de Fox; Joel Ortega, militante de la izquierda, exhortó a votar por Fox, mientras que perredistas como Genaro Santana, dirigente estatal del PRD en Oaxaca y Layda Sansores que había salido del PRI para incorporarse al PRD en 1997, se incorporaron con algunos de sus seguidores. Cabe mencionar que incluso Raúl Salinas Lozano, padre de Carlos Salinas de Gortari, luego de precisar que continuaría siendo priísta expresó: «Nunca antes como ahora el PAN está cerca de alcanzar la Presidencia de la República. Soy priísta y seguiré siendo priísta, pero a mí no me cabe duda de que Fox tiene bastante fuerza política». E. CHÁvEz. Nuevo espectáculo: oportunismo..., op. cit. Ver también M. CABILDO. También los evangélicos resultan foxistas. Proceso, 2000, $\mathrm{n}^{\circ}$ 1229, 21 de mayo, p. 26; y A. CABALLERO. Ante los cardenistas, Joel Ortega defiende su postura: hoy, la opción para derrotar al PRI se llama Fox. Proceso, 2000, nº 1229, 21 de mayo, p. 36. 
proclamaron simpatizantes de la Alianza por México ${ }^{26}$. Aun cuando Fox declaraba: «Cada vez son más los priístas serios, honestos y democráticos que se suman al cambio» (Ortiz Pardo y Ortiz Pinchetti. 2000e: 18-19) y transgredía a diario las formas y contenidos panistas, el dirigente de Acción Nacional proclamó el respaldo del panismo: «El PAN está con todo en la campaña. Nuestra estructura, nuestros recursos humanos y económicos, todo está puesto en la campaña $\gg^{27}$. En estas circunstancias, los estrategas se propusieron y consiguieron con éxito poner en práctica la «ofensiva final» a la que se denominó foximanía: «Queremos que todos den rienda suelta a su inventiva, a su imaginación, a su alegría para nutrir en toda la República el ambiente triunfalista, victorioso, motivado por las encuestas que ponen a Vicente al frente de las preferencias electorales» ${ }^{28}$.

Por su parte, y convencido de que «Vicente Fox ya llegó a su techo y va para abajo», Francisco Labastida se comprometió a «establecer una estrategia económica en la que el arreglo de la crisis no lo pague el sector mayoritario de la población $»^{29}$, mientras que dejando a un lado la promesa del «nuevo PRI», el partido recurrió sin éxito al corporativismo y para atraer la asistencia a los mítines incluso recurrió a la presentación de streaptease $e^{30}$. Para entonces, Fox había enviado una carta a los mandos medios de la burocracia asegurándoles que no perderían su empleo en el caso de que él llegara a la Presidencia y, a través de los medios masivos apeló en el mismo sentido al resto de los trabajadores del gobierno. Fue así como el candidato de la Alianza por el Cambio logró vencer uno de los obstáculos más importantes para el avance electoral de la oposición: el temor de los burócratas a perder el trabajo si el PRI perdía la presidencia de la República. Además, planteó y reiteró una y otra vez las opciones electorales: «más de lo mismo» o «sacar al PRI de Los Pinos».

26. Ellos eran: José Luis Leyson, Felipa Ramírez, Miguel Soriano, María Esther Namur, Rubén Flores. Además, perredistas que antes habían militado en el PRI, inconformes por la selección de los candidatos salieron del PRD para sumarse al PARM.

27. Al respecto, Carlos Castillo Peraza, ex dirigente nacional del PAN, manifestó: «Fox apeló al exterior del partido, para ganar el interior. Es un precedente. En el futuro eso harán los precandidatos. Y el partido puede acabar sin interior... Es un método muy corrosivo para el PAN». F. ORTIZ PARDO y F. Ortiz PinchetTi. Hacia el final de la campaña, Fox domó al Pan, Proceso, 2000, nº 1229, 21 de mayo, pp. 16-20.

28. Palabras de Juan Antonio Fernández, coordinador nacional de Amigos de Fox a F. Ortiz Pardo y F. Ortiz Pinchetti. En F. Ortiz Pardo y F. Ortiz Pinchetti. Ofensiva final: desatar la «foximanía» en todo el país. Proceso, 2000, no 1229, 21 de mayo, pp. 18-19.

29. Francisco Labastida a Carlos ACOSTA CÓRDOVA, Labastida, a todo lo que da, cuando su principal rival «llegó a su techo», Proceso, 2000, n 1229, 21 de mayo, pp. 28-29.

30. G. CORREA. Coletazos del corporativismo para salvar al PRI. Proceso, 2000, nº 1229, 21 de mayo, pp. 30-33; G. CORREA y M. L. VIVAS. Brotan organizaciones prí́stas que prometen millones de votos a Labastida. Proceso, 2000, $\mathrm{n}^{\circ}$ 1231, 4 de junio, pp. 27-29; R. MONTE. Mandos medios y altos del gobierno federal, utilizados para conseguirle votos a Labastida. Proceso, 2000, $\mathrm{n}^{\circ} 1231,4$ de junio, pp. 26-27; y A. AmBRIz. Para atraer el voto femenino, el PRI mexiquense recurre al chippendale. Proceso, 2000, nº 1231, 4 de junio, pp. 30-35. 
El 23 de mayo, cuando se llevó a cabo «el debate del debate», Fox se reafirmó como el candidato con mayores posibilidades de triunfo. Ese día, por la tarde, en la casa de campaña de Alianza por México se reunieron Cuauhtémoc Cárdenas, Vicente Fox y Francisco Labastida para acordar, en presencia de los medios de difusión masiva, el formato y fecha del segundo debate, originalmente programado para ese día, pero pospuesto por los medios en razón de que técnicamente no podían garantizar la transmisión nacional del evento. Cárdenas y Labastida aceptaron que el debate se pospusiera para el viernes 26 de mayo, Fox insistió en que se llevara a cabo por la noche conforme a lo acordado inicialmente. «El viernes», expresó Cárdenas luego de exponer los argumentos de los medios; «hoy», respondió Fox. Dos veces más insistió Cárdenas: «el viernes»y dos veces más Fox respondió «hoy». Labastida permaneció al margen de la discusión, Fox se mantuvo intransigente, mientras Cárdenas mostró un sentido del humor hasta entonces desconocido. Los representantes de los medios festejaban el comportamiento del candidato de Alianza por México y se mostraban disgustados por la actitud intransigente del candidato de Alianza por el Cambio. El encuentro, transmitido en vivo por la televisión, constituyó un acontecimiento en la historia política del país y permitió a cada espectador enjuiciar sin filtro alguno el comportamiento de cada candidato: Labastida se empequeñeció aún más, pues apenas se había notado su presencia; la espontaneidad y humor de Cárdenas sorprendió y le atrajo o reforzó simpatías; y, contra el pronóstico de sus propios estrategas que predijeron un severo retroceso en razón de la terquedad demostrada, Fox se fortaleció aún más ${ }^{31}$, hecho que confirma lo débil que resulta cualquier afirmación a priori sobre el comportamiento de los políticos y sobre los efectos de los medios: harta del régimen priísta, la opinión pública concedió su respaldo a quien había demostrado disposición para enfrentarse y no transigir. Es posible explicar la aprobación al comportamiento intransigente de Fox si se considera que, hasta entonces, las formas políticamente correctas habían resultado insuficientes para vencer «por las buenas» al régimen y al PRI, al transgredirlas, el candidato de Alianza por el Cambio demostró una manera distinta de hacer política y una seguridad absoluta de que triunfaría y se convertiría en el conductor del cambio. A partir del debate del debate, la urgencia del cambio fue subrayada una y otra vez por Vicente Fox con la palabra «hoy», que convertida por la mercadotecnia en la consigna de la campaña era expresada por el candidato y coreada por los asistentes a todos los mítines subsecuentes. De esta manera, los estrategas de Alianza por el Cambio capitalizaron lo que aparentemente había sido un error del candidato y en los actos de cierre de campaña la foximanía fue evidente (Ortiz Pardo y Ortiz Pinchetti, 2000f).

31. Tres sondeos realizados en relación con el encuentro de los tres candidatos el 23 de mayo apuntaron los siguientes resultados: Fox había triunfado de acuerdo al 34, 37 y 38 por ciento de los entrevistados; Labastida era el perdedor, al concentrar la preferencia del 19, 18 y 17 por ciento de los encuestados; mientras que Cárdenas se recuperaba al concentrar las preferencias del 19, 20 y 34 por ciento de las personas que respondieron a dichos sondeos. F. OrTIZ PARDO y F. ORTIZ PinchetTi. La historia del martes negro, en testimonio del equipo de Fox. Proceso, 2000, n ${ }^{\circ} 1230$, 28 de mayo, pp. 14-17; F. ORTIZ PARDo. Fox en el debate: seguro, jovial, logró el objetivo de su estrategia. Proceso, 2000, nº 1230, 28 de mayo, p. 16. 
Cuando la noche del 26 de mayo se realizó el debate entre los tres principales candidatos a la Presidencia, Cuauhtémoc Cárdenas preguntó una y otra vez a Francisco Labastida dónde había estado mientras gran parte del país se comprometía en la lucha por instaurar la democracia. El candidato del PRI reconoció haberse marchado como embajador a Portugal en razón de las amenazas del narcotráfico e intentó desmarcarse del salinismo. Cárdenas fue contundente: «Creo que como nadie me enfrenté al salinato; nos enfrentamos con toda decisión quienes formamos el PRD, y nadie fue tan acosado como nosotros en esa época...». Sin capacidad de respuesta, Labastida intentó sin conseguirlo evadirse y quedó fuera del debate. Fox aprovechó la oportunidad para exponer sus propuestas, se proclamó una vez más como la opción por el cambio, y luego reiteró su compromiso con México «con la pluralidad de nuestra identidad y el rescate de la grandeza y el espíritu de nuestra nación» ${ }^{32}$. Además, y sobre todo, insistió en que la jornada electoral del 2 de julio permitiría elegir entre la continuidad o el cambio.

Pese a que la polarización se ahondaba a favor de Fox, los analistas aseguraban que sólo la declinación de Cárdenas a favor de éste permitiría la alternancia ${ }^{33}$, el candidato de Alianza por el Cambio que había conservado todo el tiempo la iniciativa, triunfalista, convocó al candidato de la Alianza por México a sumarse: «Entiéndelo Cuauhtémoc: unir fuerzas. Es lo mejor para ti y para tu gente. Compartiríamos el gobierno y la responsabilidad de la transición». El candidato de Alianza por México respondió: «Gritos lastimeros de quien se sabe perdido. Si en realidad tuviera como afirma, el 40, 46 ó 48 por ciento de los votos ¿acaso me estaría llamando? ¿estaría tan desesperado como se le ve, suplicando el voto de los perredistas? $\rangle^{34}$. La ausencia de definiciones precisas que permitieran comprender la diferencia entre alternancia y transición democrática y entre un proyecto político de centro izquierda y uno de centro derecha impedía a la mayoría de los electores comprender por qué Cuauhtémoc Cárdenas se negaba a declinar a favor de Vicente Fox, incluso, segmentos importantes de la opinión pública asumieron que el candidato del PRD era cómplice del PRI en el intento de arrebatar el triunfo a la oposición foxista ${ }^{35}$.

\section{EL TRIUNFO DE FOX Y EL PREDOMINIO DEL MODELO PROPAGANDISTA}

Amigos de Fox junto con la estructura partidista de Acción Nacional anunciaron que cubrirían el 100 por ciento de las casillas electorales, también el equipo de Alianza

32. «Manifiesto a la nación mexicana» suscrito por Vicente Fox Quesada, inserto en Proceso, 2000, no 1230, 28 de mayo, pp. 42-43.

33. F. BAzÚA. En manos de Cárdenas... o de sus votantes, el triunfo de Fox, y el candidato de Alianza por el Cambio conservaba la iniciativa. Proceso, 2000, $\mathrm{n}^{\circ}$ 1232, 11 de junio, pp. 24-29.

34. Reportaje sobre el proceso electoral transmitido el 2 de julio de 2000 en CNI, Canal 40.

35. Para profundizar vid. A. BORJAS BENAVENTE. Estructura, organización interna y desempeño público del Partido de la Revolución Democrática: 1989-2000. Tesis doctoral. Universidad de Salamanca, diciembre, 2001, pp. 414-424. 
por México aseguró que contaría con representantes en todas ellas, hecho que aunado a una confianza real en el desempeño del Instituto Federal Electoral contuvo a los candidatos a no mencionar la posibilidad de un fraude electoral que además, desde su perspectiva, no se llevaría a cabo el día de la jornada electoral, sino que había sido un largo proceso determinado por la aplicación de los programas sociales del gobierno como instrumento para coaccionar el voto ${ }^{36}$. De ahí que en el transcurso de la campaña se hubieran esforzado en alertar a los ciudadanos al respecto.

Las primeras horas del 2 de julio transcurrieron en medio de una esperanza callada que eludía expresarse y que al mismo tiempo casi podía tocarse en la sonrisa de los representantes de partido y de los funcionarios de casilla, en la diligencia con la que estos últimos desempeñaban la tarea que les correspondía y, sobre todo, en la afluencia constante de votantes desde muy temprano. A diferencia de las elecciones precedentes ni los partidos de oposición ni los candidatos manifestaron desconfianza en el proceso y hacia el mediodía los integrantes de los equipos de campaña de cada contendiente se reunieron. En las instalaciones del Revolucionario Institucional los prístas se encerraron y mantuvieron un silencio que contrastaba con las tradicionales afirmaciones prematuramente triunfalistas de otros comicios. En la casa de campaña de Cuauhtémoc Cárdenas el movimiento era discreto, se percibía la incertidumbre y, en la sede del PAN había un constante ir y venir que acusaba una seguridad cautelosa, una euforia contenida.

Al comenzar la tarde los conductores de los noticiarios y los analistas políticos que comentaban en los medios de difusión la jornada electoral con base en la información recabada en las casillas comenzaron a apuntar cada vez con mayor certeza la posibilidad del cambio de régimen y muchos de los locutores que hasta entonces se habían desempeñado como voceros del gobierno y del PRI se expresaron cada vez con menos discreción partidarios de la democracia y de la conveniencia del triunfo de la oposición. Sin embargo, y aun cuando la alternancia comenzaba a vislumbrarse, aún era posible que todo se revirtiera si el presidente de la República así lo decidía.

A las veinte horas, la cadena Televisa dio a conocer el resultado de la encuesta de salida que había aplicado y que confería una ventaja de seis puntos a Vicente Fox ${ }^{37}$. Después, a las 22:45, desde la casa de campaña de Alianza por México Cuauhtémoc Cárdenas expresó: «Quiero en primer lugar agradecer, a todos aquellos que con su voto me dieron su confianza. Agradecer a quienes han estado firmes en esta lucha y consideraron que yo podía servirles y servir al país como presidente de la República. Las tendencias que muestran las encuestas de salida, las tendencias que nos muestran nuestras propias encuestas y conteos rápidos nos dejan ver que quien ha recibido el mayor número de votos en esta elección es el candidato de Alianza por el Cambio, ésta ha

36. Miguel Cabildo, M. Scherer Ibarra y R. Vera. Ejércitos del PAN, PRD y sus aliados, contra las maniobras del PRI. Proceso, 2000, no 1233, 18 de junio, pp. 18-21; G. Correa y A. Delgado. La lucha priísta por controlar las casillas. Proceso, 2000, n ${ }^{\circ} 1233,18$ de junio, pp. 32-34.

37. Vid. E. JimÉnEZ y M. SCHERER IBARRA. Nuevo objetivo de Cárdenas: «mantener a raya a Fox». Proceso, 2000, $\mathrm{n}^{\circ}$ 1235, 4 de julio, pp. 28-29. 
sido la decisión de una gran mayoría del pueblo mexicano...» ${ }^{38}$, sus colaboradores lloraban y aplaudían al mismo tiempo, pues aún cuando Cárdenas no había ganado la Presidencia de la República, el régimen priísta había llegado a su fin y la transición democrática se vislumbraba como una realidad.

Antes de las once de la noche el presidente del IFE, en transmisión nacional de los medios electrónicos, confirmó la ventaja, ya para entonces irreversible, de Vicente Fox. De esta manera, el órgano creado por iniciativa de la oposición para impulsar la democracia había cumplido con la misión que se lo había conferido: el 2 de julio se habían llevado a cabo las elecciones más vigiladas y menos impugnadas de la historia del país.

La última palabra correspondió, como hasta entonces, al titular del Ejecutivo. Pasadas las once de la noche Ernesto Zedillo manifestó: «Justo ahora el propio IFE nos ha comunicado a todos los mexicanos que cuenta ya con información, ciertamente preliminar pero suficiente y confiable, para saber que el próximo presidente de la República será el licenciado Vicente Fox Quesada» ${ }^{39}$. Minutos después, Francisco Labastida reconoció la derrota del Revolucionario Institucional. Contra todo pronóstico, sin rupturas, sin violencia, la alternancia en el poder se había producido.

Fox que durante toda la jornada electoral había actuado con moderación manifestó: «A mis adversarios en esta contienda les extiendo la mano para que con la misma determinación que competimos, demos paso a la transición en la concordia y en la renovación de las instituciones nacionales», reconoció la actuación de Zedillo: «hombre de Estado que supo entender los signos de los tiempos y facilitó la transición democrática» y convocó a todos los mexicanos «a deponer sus hostilidades para recorrer el virtuoso camino de la paz y el diálogo» ${ }^{40}$.

El pleno intercambio en el espacio público de los discursos de los políticos, periodistas y opinión pública a través de los sondeos que se produjo durante la campaña a la Presidencia del verano del 2000, permite referirse a la existencia cabal de la comunicación política en México. Desde 1988 el modelo propagandista comenzó a prevalecer

38. Las palabras de Cárdenas que siguieron a la primera cita textual fueron: «Nosotros tenemos desde las filas de esta oposición, real y firme, que seguir impulsando nuestro proyecto que es el único que puede resolver los problemas del país y del pueblo y es el único que puede encauzar a nuestro país hacía vías de independencia, de ejercicio de nuestra soberanía y de las reivindicaciones de nuestro pueblo. ¿Qué son unos cuantos días más? Aquí no hay ni puede haber desánimo ni hay flaquezas. Vamos para adelante con la misma convicción y con la misma decisión. Vamos a unirnos más estrechamente, a fortalecer nuestras organizaciones, a superar diferencias. La lucha evidentemente no será fácil, quizá vaya a ser más difícil, más obstáculos, más resistencias, en otros campos en los que hasta ahora no nos hemos encontrado luchando con la misma necesidad con la que hemos tenido que hacerlo hasta estos momentos, pero aquí estamos, seguiremos juntos, seremos más, tenemos la razón, nos movemos en el sentido de la historia y estamos seguros que con México a la victoria». Discurso pronunciado por Cuauhtémoc Cárdenas Solórzano a las 22:45 del 2 de julio y transmitido en vivo por los medios electrónicos.

39. Discurso pronunciado por el presidente Ernesto Zedillo a las 23:02 horas del 2 de julio de 2000 y transmitido en vivo por cadena nacional a través de los medios de difusión electrónicos.

40. Discurso pronunciado por Vicente Fox Quesada a las 23:40 horas del 2 de julio de 2000 y transmitido en vivo por cadena nacional a través de los medios de difusión electrónicos. 
sobre diversos aspectos del modelo dialógico, pero fue a partir de la campaña desarrollada por Vicente Fox y, sobre todo, a consecuencia de los resultados obtenidos por éste, que hoy puede considerarse dicho modelo como el predominante en la comunicación política del país, hecho que obliga a los actores políticos a definir estrategias y estructurar discursos conforme a las pautas establecidas por dicho modelo.

\section{BIBLIOGRAFÍA}

ACHACHE, G. El marketing político. En FerRY, J. M.; Wolton, D. et al. El nuevo espacio público. Barcelona: Gedisa, 1998.

Ambriz, A. Para atraer el voto femenino, el PRI mexiquense recurre al chippendale. Proceso, 2000, no 1231, 4 de junio, pp. 30-35.

Baducco, G. La muerte de las mariposas. Día siete, 2001, nº 54, 1 de julio, pp. 20-27.

BAzÚA, F. En manos de Cárdenas... o de sus votantes, el triunfo de Fox. Proceso, 2000, nº 1232, 11 de junio, pp. 24-29.

BELTRÁN DEL RíO, P. En su precampaña presidencial Fox recurre a lemas utilizados por el PSOE y Clinton. Proceso, 1998, n ${ }^{\circ} 1141,13$ de septiembre, p. 25.

Borjas Benavente, A. Estrategias de campaña del PRI, del PAN y del PRD en las elecciones del Distrito Federal de 1997. Comunicación presentada en el III Congreso Español de Ciencia Política y de la Administración. España, Salamanca, octubre, 1997.

Borjas Benavente, A. Estructura, organización interna y desempeño público del Partido de la Revolución Democrática: 1989-2000. Tesis doctoral. España: Universidad de Salamanca, diciembre, 2001.

Bregman, D. La función de agenda: una problemática de transformación. En FERRY, J. M.; WOLTON, D. et al. El nuevo espacio público. Barcelona: Gedisa, 1998.

Caballero, A. Ante los cardenistas, Joel Ortega defiende su postura: hoy, la opción para derrotar al PRI se llama Fox. Proceso, 2000, nº 1229, 21 de mayo, p. 36.

Cabildo, M. También los evangélicos resultan foxistas. Proceso, 2000, n 1229, 21 de mayo, p. 26.

CABILDO, M.; SCHERER IBARRA, M. y VERA, R. Ejércitos del PAN, PRD y sus aliados, contra las maniobras del PRI. Proceso, 2000, n 1233, 18 de junio, pp. 18-21.

CASTAÑEDA, Jorge G. La herencia. Arqueología de la sucesión presidencial. México: Extra Alfaguara, 1999.

CorreA, G. y Vivas, M. L. Brotan organizaciones príistas que prometen millones de votos a Labastida. Proceso, 2000, n 1231, 4 de junio, pp. 27-29.

Correa, G. Coletazos del corporativismo para salvar al PRi. Proceso, 2000, nº 1229, 21 de mayo, pp. 30-33.

Correa, G. y Delgado, A. La lucha priísta por controlar las casillas. Proceso, 2000, n 1233, 18 de junio, pp. 32-34.

Corro, S. Todos contra todos. Proceso, 2000, $\mathrm{n}^{\circ}$ 1228, 14 de mayo, pp. 10-14.

Del Rey MoRató, J. Los juegos de los políticos. Teoría general de la información y comunicación política. Madrid: Tecnos, 1997.

DELGADO, A. «Daños irreparables» al proceso electoral por la guerra de spots entre el IFE y la CIRT. Proceso, 2000, $\mathrm{n}^{\circ} 1226,30$ de abril, pp. 32-35.

- Cárdenas y el PRD: historia de una declinación imposible. Proceso, 2000, nº 1228, 14 de mayo, pp. 26-27. 
- Montaño defiende a RTC y advierte: los concesionarios tendrán que reponer los spots que no transmitieron. Proceso, n ${ }^{\circ} 1226$, p. 34.

Encuesta de la empresa Indermec Louis Harris.

Fox Quesada, V. Manifiesto a la nación mexicana. Proceso, 2000, n 1230, 28 de mayo, pp. 42-43.

JimÉnEZ, E. y SCHERER IbARRA, M. Nuevo objetivo de Cárdenas: mantener a raya a Fox. Proceso, 2000, no 1235,4 de julio, pp. 28-29.

MonsivÁIs, C. La vocación del aliviane. Proceso, 1999, no 1194, 19 de septiembre, pp. 28-32.

Monte, R. Mandos medios y altos del gobierno federal, utilizados para conseguirle votos a Labastida. Proceso, 2000, n 1231,4 de junio, pp. 26-27.

Noelle-Neumann, E. La espiral del silencio. Una teoría de la opinión. FerRY, J. M.; Wolton, D. et al. El nuevo espacio público. Barcelona: Gedisa, 1998.

Ortiz PARDO, F. Fox en el debate: seguro, jovial, logró el objetivo de su estrategia. Proceso, 2000, $\mathrm{n}^{\mathrm{o}} 1230,28$ de mayo, p. 16.

Ortiz Pardo, F. y Ortiz Pinchetti, F. En detalle, la gigantesca organización que mueve a Fox. Proceso, 2000a, no 1215, 13 de febrero, pp. 28-31.

- Fox en campaña: ropa y comportamiento, según el auditorio. Proceso, 2000b, n 1215,13 de febrero, p. 31.

- Hacia el final de la campaña, Fox domó al PAN. Proceso, 2000c, nº 1229, 21 de mayo, pp. 16-20.

- La historia del martes negro, en testimonio del equipo de Fox. Proceso, 2000d, no 1230, 28 de mayo, pp. 14-17.

- Ofensiva final: desatar la «foximanía» en todo el país. Proceso, 2000e, n 1229, 21 de mayo, pp. 18-19.

- Fox en sus cierres de campaña, con su nuevo lema: ¡hoy! ¡hoy! ¡hoy! Proceso, 2000f, n 1231, 4 de junio, pp. 19-21.

Ortiz PinchetTi, F. El estilo de Fox soporta hasta contradicciones y deslices. Proceso, 2000, $\mathrm{n}^{\circ}$ 1219, 12 de marzo, pp. 10-15.

ORTIZ PINCHETTI, F. y ORTIZ PARDO, F. Ahora, la prioridad foxista es alcanzar un acuerdo nacional. Proceso, 2000, n 1226, 30 de abril, pp. 20-21

Panebianco, A. Comunicación política. En Bobbio, N.; Mateucci, N. y Pasquino, G. Diccionario de política. México: Siglo Veintiuno Editores, 1997.

Ponce, A. Distribuir computadoras, otra forma de repartir miseria. Proceso, 2000, nº 1224, 16 de abril, pp. 14-18.

Sartori, G. Partidos y sistemas de partidos. Madrid: Alianza Universidad, 1992.

Wolton, D. La comunicación política: construcción de un modelo. En FERrY, J. M; Wolton, D. et al. El nuevo espacio público, Barcelona: Gedisa, 1998. 